\title{
MONOGRÁFICO
}

\section{Cervantes en el SIglo XVIII}

\author{
Coordinado por \\ Emilio Martínez Mata \\ Instituto Feijoo de Estudios del Siglo XVIII \\ Universidad de Oviedo
}


El presente monográfico presenta algunos resultados del proyecto de investigación «Recepción e interpretación del Quijote (16051830). Traducciones, opiniones, recreaciones», del Plan Nacional de Investigación Científica, Desarrollo e Innovación Tecnológica (FFI2014-56414-P). Dicho proyecto se desarrolla en el ámbito del Grupo de Estudios Cervantinos (GREC), constituido en la Universidad de Oviedo. 
Nota preliminar

\section{Cervantes en el siglo XVIII}

Cervantes in eighteenth-century

Emilio Martínez Mata

Instituto Feijoo de Estudios del Siglo XVIII

Universidad de Oviedo 

El siglo XVIII (sin limitarlo estrictamente a la centuria, es decir, abarcando también los años finales del siglo anterior y los iniciales del siguiente) resulta crucial en la trayectoria del Quijote. Le rescata de la interpretación como libro de caballerías burlesco, una condición que le abocaría a una vía sin salida, en la que empezaba ya a languidecer, y, por el contrario, le va a proporcionar una gigantesca proyección al convertirlo en el fundamento de la novela moderna ${ }^{1}$. El traductor de la versión alemana del Quijote de 1775, Bertuch, expresa con clarividencia, a la vez que refleja la sensibilidad de su tiempo, cómo el cambio de interpretación dota al Quijote de una nueva vida: «Si el genio de Cervantes no hubiera sido superior [...] y su Don Quijote no hubiera sido más que una sátira de los libros de caballerías, probablemente habría sido olvidado ya desde hace mucho tiempo y no sabríamos nada de sus escritos».

El modelo narrativo cervantino es el origen del enorme cambio que va a experimentar la novela gracias a los principales novelistas ingleses, Fielding, Smollet, Sterne, quienes, junto con Richardson, van a convertir a la novela en el género de moda, el que provocará un extraordinario incremento del público lector y se convertirá en punto de partida de la gran novela del siglo XIX, también de influencia cervantina (Jane Austen, Dickens, Melville, Stendhal, Flaubert, Turgeniev, Dostoieivsky, Tolstoi, Galdós, Clarín, etc.).

Además, a finales del siglo XVIII los escritores alemanes van a gestar la llamada interpretación romántica del Quijote, la culpable del desarrollo del mito del Quijote como representación simbólica de la lucha del ideal contra la realidad, del sujeto contra el mundo, una interpretación difundida de un modo masivo en la cultura occidental hasta nuestros días.

Nada de esto habría sido posible si la Ilustración no hubiera proyectado sobre el Quijote una mirada bien diferente. De ahí que se multipliquen los trabajos

$1 \quad$ Una explicación sobre el cambio de interpretación producido en ese momento puede verse en Emilio Martínez Mata, «El cambio de interpretación del Quijote: de libro de burlas a obra clásica», en Cervantes y el «Quijote». Actas del coloquio internacional (Oviedo, 27 al 29 de octubre de 2004), Arco/Libros, Madrid, 2007, págs. 197-213. Sobre una de las razones del papel del Quijote en el nacimiento de la novela moderna puede verse Emilio MartínEz Mata, «Don Quixote in the birth of modern novel: the satirical interpretation», en Don Quixote: The Re-accentuation of the World's Greatest Literary Hero, ed. Howard Mancing y Viatcheslav Gratchev, Bucknell University Press (en prensa). 
sobre el tema en los últimos años después de los pioneros de Paolo Cherchi y Anthony Close 2 . Cuadernos de Estudios del Siglo XVIII no podría mantenerse al margen de ese interés, coincidiendo además con el centenario del fallecimiento de Miguel de Cervantes.

Las lecturas y las valoraciones no fueron similares ni mucho menos en las distintas naciones. Recordemos que el interés por una biografía de Cervantes, reflejo de una concepción del Quijote bien distinta de la de libro de caballerías burlesco, se inicia en Inglaterra en 1700 con la traducción de Peter Motteux, que incorpora una breve síntesis biográfica del novelista. La biografía de Miguel de Cervantes de Mayans, que tanto éxito va a alcanzar en toda Europa al incorporarse como introducción a traducciones inglesas o alemanas del Quijote, es el resultado de un encargo de lord Carteret para su edición de 1738 transmitido por el embajador inglés, Benjamin Keene. Antes del encargo, Mayans no había mostrado especial aprecio por Cervantes y su actitud hacia el éxito de su biografía de Cervantes será más bien despectiva. Hasta el último tercio del siglo no se despierta en España un verdadero interés por la figura de Cervantes, con la excepción de Cadalso, de quien se ocupa en este número Eli Cohen.

Atendiendo a la importancia del Quijote en el nacimiento de la novela moderna, Juan Garrido Ardila efectúa una revisión de las diferentes trayectorias de la crítica que se ha ocupado de la influencia del Quijote en la novela inglesa del siglo XVIII y el papel otorgado a esa influencia en el nacimiento de la novela moderna. Contrapone la influencia de la picaresca española en la narrativa inglesa del XVII con la del Quijote en la del XVIII, explicándola por un común interés en el realismo, frente al carácter irrealista de la novela sentimental francesa, aunque con una muy superior ambición formal de los novelistas del XVIII, que encontrarían en el Quijote una contextura formal mucho más compacta.

Establece una clasificación de la narrativa influida por el Quijote en dos grupos: las novelas de temática quijotesca (las Quixotic fictions) y las inspiradas en las características formales del Quijote (las Cervantean novels). Además de revisar de un modo sintético la amplísima bibliografía sobre el tema, señala los campos abiertos todavía a la investigación y concluye resumiendo la poética cervantina en siete rasgos: 1) el protagonista quijotesco, 2) la imitación de personajes cervantinos, 3) el calco de pasajes o episodios del Quijote, 4) la comicidad irónica, 5) el carácter paródico y satírico, 6) la estructura narratológica (es decir, la urdidumbre diegética y la metaficción) y 7) su hibridismo genérico.

2 Paolo Cherchi, Capitoli di critica cervantina (160+5-1789), Roma, Bulzoni (Biblioteca di Cultura, 96), 1977. Anthony J. Close, The Romantic Approach of «Don Quijote». A Critical History of the Romantic Tradition in «Quixote» Criticism, Cambridge, Cambridge University Press, 1978; trad. esp.: La concepción romántica del "Quijote", Barcelona, Crítica, 2005. 
Dentro de ese mismo ámbito, el de la influencia del Quijote en la novela inglesa del xvIII, Pablo J. Carvajal Pedraza dedica su artículo al personaje de Benjamin Partridge de la novela Tom Jones (1749) del inglés Henry Fielding, trazando su ascendencia sanchopancesca a través de un análisis detallado de todos aquellos rasgos derivados del personaje de Cervantes. Resulta de especial interés cómo el novelista inglés reelabora en su personaje algunos de los recursos más sobresalientes del habla de Sancho Panza, como el uso indiscriminado de refranes o el discurso en circunloquio, para caracterizar al compañero de desventuras de Tom Jones, un antiguo maestro de latín devenido en barberocirujano, quien sazona su habla con toda una serie de latinajos, casi siempre innecesarios, redundantes y mal aplicados al tema, unidos a un discurso en el que se sitúan al mismo nivel tanto las informaciones relevantes como aquellas meramente accesorias o innecesarias, consiguiendo un efecto cómico muy similar al que logra Cervantes con Sancho; un discurso en el que la agudeza y la simplicidad de ambos personajes conviven de forma inseparable.

Además de estudiar las semejanzas en la construcción del habla de estos dos personajes, Pablo Carvajal analiza también otro buen número de rasgos que se encuentran en Partridge y que proceden del escudero español, tales como el carácter medroso y supersticioso, la glotonería y afición a la bebida, el interés materialista de su empresa o su rol como mediador entre su señor y la amada de este. En su análisis, no se olvida de recoger las similitudes con otro personaje, antecedente inmediato de Partridge, Hugh Strap, de la novela Roderick Random (1748), de Tobias Smollett, así como de señalar un primer acercamiento por parte de Fielding al personaje cervantino y a sus rasgos más característicos en la obra teatral Don Quixote in England (1728).

$\mathrm{Al}$ ámbito de la recepción francesa del Quijote en el entorno de la Revolución francesa se dedican los artículos de Esther Bautista y Clark Colahan. Esther Bautista, por su parte, se plantea el examen de las interpretaciones del Quijote en Francia en el Siglo de las Luces tomando como eje las interpretaciones anteriores y posteriores a la Revolución. Las lecturas examinadas muestran interpretaciones simbólicas que irían en sincronía con el inicio de la concepción romántica de la novela cervantina. No limita el objetivo de su trabajo a las interpretaciones del periodo revolucionario, sino que su revisión de antecedentes y consecuencias se convierte en un repaso de la lectura del Quijote en la Ilustración francesa. Esa específica trayectoria se iniciaría con la traducción de Filleau de Saint-Martin, que proporciona un texto con un lenguaje más sencillo y cercano, a la vez que rebaja ligeramente el tono cómico y jocoso para proporcionar una mirada más comprensiva del personaje, cuya honestidad destaca en medio de un entorno hostil. 
El contexto histórico de la Revolución va a propiciar una lectura del Quijote que relega los aspectos cómicos y los de crítica social para dar paso a un énfasis en su sentido ético: la lucha del individuo frente a la sociedad. La creciente popularidad del Quijote, perceptible también en la frecuencia de alusiones al personaje en contextos no literarios, le permitiría superar la hostilidad francesa hacia España, a la vez que va a resultar utilizado por los diferentes bandos con valores simbólicos bien distintos.

Si bien el Quijote no obtiene el éxito que alcanza en Alemania entre los grandes escritores, siendo su difusión en la Francia revolucionaria de naturaleza más popular, en opinión de Esther Bautista, se desarrolla en cambio una interpretación simbólica que podía conectar muy bien con la concepción romántica: la del idealismo que no duda en ofrecer la vida en nombre de un principio moral superior.

Clark Colahan indaga en su estudio en la transformación de ciertos elementos del Quijote en la Galatée (1783) de Jean-Pierre Claris de Florian. Aunque la presencia de Cervantes en la obra del francés ya ha sido estudiada con anterioridad, especialmente en lo que se refiere a la depuración del lenguaje de la Galatea para adecuarlo a los gustos franceses de finales del XVIII, así como su remodelación formal (reducción a tres de los seis libros de la novela pastoril cervantina, supresión de tramas y adición de un cuarto volumen que cierra la obra), un aspecto desatendido hasta este momento es el de la transformación de ciertas imágenes, motivos y personajes del mundo paródico del Quijote al ambiente idealizado y de finalidad didáctica de la Galatée, proceso compartido además, tanto en determinadas imágenes como en el tono, con el Persiles.

Analiza varias de estas imágenes visuales y personajes, mostrando el proceso de transformación -en ocasiones incluso de inversión- al que son sometidas por parte de Florian y de las que aprovecha sus posibilidades simbólicas y didácticas, muy en consonancia con su perfil ilustrado y de autor de fábulas. De entre estas imágenes, Colahan se detiene en varias relacionadas con animales para mostrar este proceso.

En otros casos, como en el de los pastores Fabian y Artidore, basados en Cardenio, la transformación no supone tanto una inversión como una reelaboración de ciertos elementos: la locura derivada de un malentendido, la vida como hombres salvajes, el enredo amoroso o la vuelta a la cordura a través de la mediación de una mujer.

En relación con la interpretación italiana del Quijote, Franco Quinziano destaca cómo, frente a la pobreza crítica y ausencia de actividad traductora, en el setecientos italiano se produce una gran utilización del Quijote en el drama musical, convirtiéndose en el mito más frecuente en los géneros y subgéneros musicales: farsas, intermezzi, ballets, contrascene per musica, óperas bufas, 
serias, pantomimas, etc. Los episodios más recreados son los que suceden en Sierra Morena, los del palacio de los duques y los relativos al gobierno de Sancho. Analiza dos intermezzi musicales de mediados de siglo, Don Chisciotte a Venezia, de Giuseppe Baretti, y Don Chisciotte nella selva di Alcina, de Francesco Corsetti. Baretti, gran conocedor de la cultura hispánica y de la obra de Cervantes, recrea libremente el episodio del retablo de Maese Pedro y el encantamiento de Dulcinea. En la obra de Corsetti, compuesta para ser representada con ocasión del carnaval, se reelaboran motivos cervantinos para situarlos en un contexto caballeresco y folclórico bien conocido en la Italia central. El resultado en los dos intermezzi es la recreación de temas y personajes cervantinos en clave burlesca, casi caricaturesca. Si en la farsa de Baretti se percibe una clara predilección por el recuerdo cómico de la locura del protagonista, en la de Corsetti predomina el miedo a lo sobrenatural y la condena de la ambición desmedida. El resultado es que en las dos recreaciones don Quijote es presentado como un personaje alocado, cobarde y ambicioso.

De la interpretación española se ocupan Eli Cohen, Jesús Pérez Magallón y Francisco Cuevas. Eli Cohen examina, a partir de la identificación con el Quijote que efectúa Cadalso en la «Introducción» de sus Cartas marruecas, los rasgos novelísticos de la obra cervantina que Cadalso habría incorporado a la suya. A pesar de la diversidad temática y formal entre las dos obras, la manifestación tan clara y tajante con que inicia Cadalso su «Introducción» reclamando el modelo crítico cervantino, junto con el epistolar entonces de moda, estaría proclamando una afinidad genérica (discutida con frecuencia por la crítica). Las palabras de Cadalso reflejarían, en la opinión de Eli Cohen, que Cadalso recogería de Cervantes la idea de la variedad de la obra como una forma de responder adecuadamente a la heterogeneidad de los lectores, aun cuando Cadalso manifieste una aparente desconfianza hacia la recepción que puedan hacer los lectores. La apelación al lector y a su esfuerzo interpretativo se encontraría también en el juego irónico con el tópico de la ambigua relación entre texto y autor, que Cadalso imita al presentar la obra como un supuesto manuscrito que ha llegado a sus manos por la muerte de un conocido. De este modo, el texto adquiriría, según la interpretación de Eli Cohen, una supuesta autonomía al ponerse en duda, con la ruptura de la relación directa entre autor y texto, el dominio del autor sobre su obra.

Jesús Pérez Magallón revisa las dos intervenciones de Goya sobre el Quijote: el grabado que le encarga la Academia para la edición de 1780, aunque no llega a publicarse, sobre el episodio del pueblo del rebuzno; y el dibujo que llevó a cabo en uno de sus cuadernos (el álbum F), conservado en el British Museum: el hidalgo leyendo en su biblioteca. Sus observaciones sobre las dos 
imágenes vienen precedidas por la reflexión sobre algunos de los aspectos biográficos del pintor como contexto necesario para entenderlas cabalmente, en cuanto que en esas imágenes se podría sintetizar la trayectoria de Goya como grabador y dibujante. Tras examinar algunos de los problemas interpretativos que plantean las dos imágenes, concluye que la explicación de por qué no fue elegido su dibujo para la Academia habría que buscarla en la desobediencia a las instrucciones que había proporcionado la propia Academia.

Con la consagración en las naciones europeas del Quijote como un clásico surgiría el interés por la biografía de su autor. Aunque ese interés no fructificaría - a excepción del encargo a Mayans y alguna atención ocasional, como la de Sarmiento - hasta la biografía de Juan Antonio Pellicer y Saforcada impresa en 1778, dentro de su Ensayo de una biblioteca de traductores españoles, ampliada y reescrita en 1797. Si la biografía de Cervantes de Mayans se basaba únicamente en lo que Cervantes declara de sí mismo en sus obras, relegando la biografía como tal ante el predominio del análisis literario de las obras, la de Pellicer será la primera en utilizar un corpus documental para reconstruir la vida del escritor. Francisco Cuevas va a revisar paso por paso esa biografía, además de valorar sus consecuencias en el cervantismo. Resalta el carácter erudito del trabajo de Pellicer, especialmente en la versión de 1797, que recoge una ingente cantidad de datos sobre la época y sobre autores coetáneos a Cervantes. Esa atención a datos y documentos de la época para explicar la vida del escritor, un proceder en dirección contraria a lo que se había hecho hasta entonces, proporcionaría a la Vida de Cervantes de 1797 un carácter heterogéneo y desigual, con mayor dispersión de lo deseable.

Francisco Cuevas comenta de modo particular los datos históricos de la vida de Cervantes proporcionados por Pellicer que resultan más controvertidos. Es el caso de los documentos sobre la partida de rescate publicados por Pellicer, con datos contradictorios o incómodos — para la imagen del escritor- sobre la madre y la hermana de Cervantes, o los referidos al proceso acerca del asesinato de Gaspar de Ezpeleta a las puertas del domicilio de Cervantes, con informaciones poco edificantes acerca de las mujeres que viven con él. Francisco Cuevas repasa también otras cuestiones suscitadas por la biografía de Pellicer, como la enemistad con Lope y la identificación de poesías sueltas de Cervantes relacionadas con su biografía. 